\title{
BMJ Open To 'Get by' or 'get help'? A qualitative study of physicians' challenges and dilemmas when patients have limited English proficiency
}

\author{
Janet A Parsons, ${ }^{1,2}$ Natalie A Baker, ${ }^{1}$ Telisha Smith-Gorvie, ${ }^{3,4}$ Pamela L Hudak ${ }^{5}$
}

To cite: Parsons JA, Baker NA, Smith-Gorvie T, et al. To 'Get by' or 'get help'? A qualitative study of physicians' challenges and dilemmas when patients have limited English proficiency. BMJ Open 2014;4:e004613. doi:10.1136/ bmjopen-2013-004613

- Prepublication history and additional material is available. To view please visit the journal (http://dx.doi.org/ 10.1136/bmjopen-2013004613).

Received 3 December 2013 Revised 25 April 2014 Accepted 29 April 2014

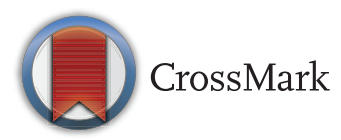

For numbered affiliations see end of article.

Correspondence to Dr Janet A Parsons: parsonsj@smh.ca

\section{ABSTRACT}

Objective: Encounters between patients and physicians who do not speak the same language are relatively common in Canada, particularly in urban settings; this trend is increasing worldwide. Language discordance has important effects on health outcomes, including mortality. This study sought to explore physicians' experiences of care provision in situations of language discordance in depth.

Design: Qualitative study based on individual interviews. Interview guides elicited physicians' perspectives on how they determined whether communication could proceed unaided. A descriptive qualitative approach was adopted, entailing inductive thematic analysis.

Participants: 22 physicians experienced in treating patients in situations of language discordance were recruited from the emergency and internal medicine departments of an urban tertiary-care hospital.

Setting: Large, inner-city teaching hospital in Toronto, Canada, one of the most linguistically diverse cities internationally.

Results: Determining when to 'get by' or 'get help' in order to facilitate communication was described as a fluid and variable process. Deciding which strategy to use depended on three inter-related factors: time/time constraints, acuity of situation and ease of use/availability of translation aids. Participants reported at times feeling conflicted about their decisions, portraying some of these clinical encounters as a 'troubling space' in which they experienced one or more dilemmas related to real versus ideal practice, responsibility and informed consent.

Conclusions: In situations of language discordance, a physician's decision to 'get by' (vs 'get help') rests on a judgement of whether communication can be considered 'good enough' to proceed and depends on the circumstances of the specific encounter. The tension set up between what is 'ideal' and what is practically possible can be experienced as a dilemma by physicians. The study's findings have implications for practice and policy not only in Canada but in other multilingual settings, and indicate that physicians require greater support.

\section{INTRODUCTION}

Clear communication has long been recognised as integral to high-quality medical care.

\section{Strengths and limitations of this study}

- There are few in-depth studies documenting physicians' experiences of language discordance in Canada or elsewhere.

- Qualitative methodology is well-suited to exploring physicians' experiences of communication and care provision.

- The study deepens our understanding of how physicians decide whether to 'get by' or 'get help' in situations of language discordance, and the dilemmas that physicians can experience.

- A limitation is that this was a single-site study with participants from only two medical specialties; nevertheless, the concepts generated are transferrable to other practice settings.

However, physicians frequently encounter situations where effective communication is difficult. One such situation is when physicians and patients do not speak the same language-referred to as language discordance. ${ }^{1}$ Increasing globalisation, human migration ${ }^{2}$ and travel mean that many countries are becoming more and more multilingual, and this is especially true of urban centres. ${ }^{3}$ Although Canada has two official languages (English and French), it is a nation with many immigrants, representing an array of linguistic traditions. New immigrants may not speak either official language. Major cities are popular settlement areas for new immigrants, thus physicians are extremely likely to encounter patients who do not speak the dominant language. This matters because language barriers can be a source of health disparity, including differential mortality rates. ${ }^{1}$ In a Canadian study on tuberculosis, mortality risk was significantly higher $(\mathrm{HR}=2.32 ; 95 \%$ CI 1.39 to $3.88, \mathrm{p}<0.001$ ) in situations of language discordance. ${ }^{1}$ Language barriers have been shown to: impair patient comprehen$\operatorname{sion}^{4}$; act as a barrier to accessing care $^{5-7}$; negatively affect treatment adherence ${ }^{89}$ and affect satisfaction with care. ${ }^{10-12}$ Language 
barriers are also associated with increased hospital length-of-stay, ${ }^{13}$ and decreased self-reported health status. $^{14}$

In addition to patients and physicians not sharing a language, social structural features of medical practice can further compound the situation. The fast pace of modern clinical practice has been identified as a challenge to effective communication because decisions must be made quickly and are often history-dependent. Although there is literature documenting outcomes associated with language discordance, there is relatively little comprehensive research into physicians' experiences of language discordance generally. Moreover, there is a paucity of research eliciting Canadian physicians' perspectives on the topic. One survey-based study of Montreal family physicians focused on their attitudes towards caring for immigrant patients, with $77 \%$ reporting that communication was the greatest barrier to patient management. ${ }^{15}$ Another recent study surveyed physicians from Manitoba, Canada, on factors affecting communication with patients of different cultural and socioeconomic backgrounds, with an emphasis on process errors and their relationship not only to language discordance, but a host of other factors, such as patient age, gender and trust. ${ }^{16}$ Neither of these studies offers in-depth exploration of physicians' experiences of caring for patients in situations of language discordance. This gap can only be addressed by speaking to physicians directly, using qualitative methods. Understanding physicians' experiences is vital, given that language barriers are known to translate into negative outcomes for

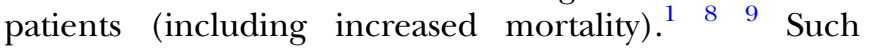
studies will yield important contextual information about patient care in situations of language discordance, identifying opportunities for (and barriers to) improvement and informing practice renewal.

Our study explores physicians' experiences of interacting with patients for whom language proficiency (in this case, limited English proficiency or LEP) ${ }^{17} 18$ was perceived to hinder effective communication. LEP is a term used to describe individuals who do not speak English as their primary language and who have a limited ability to read, speak, write or understand English. ${ }^{13}{ }^{14}$ We use 'LEP' interchangeably with 'language discordance'. In this paper, we highlight conditions and strategies associated with circumstances in which physicians 'get by' or 'get help' in these encounters.

\section{METHODS}

This study focuses on physicians' practice experiences where LEP was perceived to be the main factor hindering effective communication with patients. These accounts encompassed an array of situations, including those in which the physician and patient had any of the following: no shared language, some shared language, comprehension issues related to accents, situations where no translation aids were used or those where different types of translation aids were used. We did not consider situations where communication was influenced by a patient's inability to speak as a result of aphasia or some other cognitive or mechanical issue.

\section{Setting}

The study was conducted in Toronto, Canada's most multicultural city, with over 160 languages spoken. ${ }^{19}$ English is the dominant language. The study institution, a tertiary-care teaching hospital, serves patients diverse in language and culture and its physicians are likely to have significant clinical experience with LEP patients. Written informed consent was obtained from all participants.

\section{Sample}

All staff physicians and senior residents in the hospital's departments of internal medicine and emergency medicine were eligible for inclusion. Participants were invited to share their experiences 'when challenges to communication secondary to language discordance are encountered in routine clinical practice'. Twenty-two physicians agreed to participate, including men $(n=17)$ and women $(n=5)$, with a wide range of years of clinical experience (mean: 10.7; range: 1-28).

\section{Data collection}

Semistructured audiotaped interviews were conducted, lasting $1 \mathrm{~h}$ on average. The interview guide was developed by researchers with practice and methodological expertise, and pilot tested with three participants. ${ }^{20}$ Following pilot testing the wording was modified to improve clarity of some questions, but no substantive changes to content were required. Questions focused on how physicians determine whether communication is adequate to proceed unaided. They were asked to recall clinical encounters where (1) they did not share a language with the patient/family member and (2) they shared a language but not at the same proficiency. Details were probed concerning: (1) conditions under which physicians feel they need to get help; (2) strategies employed to facilitate communication; (3) what they say they usually do when working with LEP patients and (4) how they feel about what they do. A copy of the interview guide appears in the online supplementary appendix. All interviews occurred in the Summer and Fall of 2009.

\section{Data analysis}

Interviews were transcribed and analysed using an approach of qualitative descriptive analysis (as described by Sandelowski), in order to inductively identify, code and categorise patterns in the data. ${ }^{21-25}$ The senior investigator began by reading the interviews closely, identifying key themes and patterns, reviewing the data multiple times and developing codes as new topics and relationships were identified. ${ }^{26}{ }^{27}$ At this early stage, an experienced qualitative researcher who was not part of the 
research team also reviewed several transcripts and made independent observations. A preliminary coding scheme was developed and applied to all transcripts. ${ }^{24}{ }^{25}$ Analytic rigour was aided by continual re-examination of the data by all authors throughout the research process. ${ }^{28} 29$

\section{RESULTS}

A key early insight was that participants' accounts could be viewed as describing the conditions under which physicians 'get by' in a clinical encounter even when language proficiency is not shared, in contrast to when they decide that they must 'get help' to proceed further. Getting by means proceeding with the interaction without seeking assistance. Getting help entails pausing the interaction to seek translation/interpretation services or tools. Deciding which strategy to employ was depicted as context-driven, and primarily dependent on three factors: time constraints, patient acuity and ease/availability of translation assistance/aids. Decision-making was sometimes portrayed as 'troubling', a process characterised by three overlapping dilemmas, the gap between real versus ideal practice, the notion of responsibility and the issue of informed consent. Table 1 includes quotes supporting the findings outlined below.

\section{To 'get by' or 'get help'?}

Participants encountered many different languages in their practice settings. Typically, another member of the healthcare team informed physicians of a patient's LEP status (verbally or in writing), and whether a translator was available. Participants recounted that they then validated the patient's LEP status independently, using verbal and non-verbal cues (eg, gestures, facial expressions) to gauge understanding (eg, purposely asking open-ended questions). On identifying a language barrier, they then described a process of weighing whether they could 'get by' or whether they should 'get help'.

In some cases, physicians would 'get by' with what they can glean from a patient without shared language. These situations were described by one physician as the "grey zone" in which a patient's "level of English proficiency is good enough so that maybe you can feel that you can get by but their comprehension may in fact be poor enough that they can get into trouble" (90615). The tendency in these cases is to 'follow the path of least resistance' that is, getting by with any resources readily available.

Choosing to 'get by' without additional assistance can include any of the following strategies: speaking more slowly, enunciating more carefully, using plain language and requesting that the patient paraphrase instructions to gauge understanding. Participants perceived situations of limited/imperfect communication as 'risky'. They compensated by proceeding with caution-giving patients more time than usual, double checking test results, ordering more tests or keeping patients longer for observation. As a result, clinical assessments tended to privilege objective findings over subjective reports.
Participants also described situations where they considered it too risky to proceed without confidence in communication quality: for example, attempting to determine medication side effects, or discussing end-of-life care. 'Getting help' ranged from using professional translators/interpreters, to having other staff or family members translate, to using the language line. ${ }^{18}$ In our study, the term 'language line' is used to describe telephone interpretation via single or dual handset phones whereby the interpreter is located outside of the immediate clinical setting, providing real-time interpretation as the parties speak. ${ }^{23}$ This has been referred to as 'UN-style interpretation'(ref. ${ }^{23}$, p.741). Overall participants indicated that, when time permitted, their preference of use, in descending order, was: professional interpreters (first choice), then the language line and finally other hospital staff or family members.

\section{Acuity/severity of illness, time constraints and ease/ availability of translation aids}

Choosing whether to 'get by' or 'get help' hinged on several interlinked factors. The patient's clinical status and their relative acuity was commonly mentioned as a primary factor for consideration. For example, a physician recounted a situation where a patient presented with signs of stroke. He elected to 'get by' due to the urgency of the situation and the potential consequences of delaying definitive care; the patient subsequently recovered. This participant acknowledged that 'getting by' entailed proceeding with 'imperfect information', treating 'more of what they could see rather than the symptoms' (90706). Although the physician considered this less-than-ideal, 'getting by' often trumped 'getting help' in emergency situations. Conversely, if a case involves, for example, providing discharge instructions to a stable patient, participants said they felt they had 'time on their side' to await a translator. The interaction between a less-acute situation and available time highlights the inter-relatedness of clinical status with a second factor, time. However, there was no simple equation for determining whether to 'get by' or 'get help' vis-à-vis clinical status: 'it's a judgment call...it's more of an art than a science' (90901).

Time is another factor informing physicians' decisionmaking. Participants depicted choosing the most pragmatic path of care when faced with time-related constraints. Many physicians described the significant time and effort involved in obtaining relevant clinical information from LEP patients. They told of 'verifying, inferring, checking charts, checking with pharmacist, etc.' (90710). Time could be an issue even when a translator is available because this 'doubles the duration of the interaction so everything takes twice as long' (90728) which is suboptimal in emergencies. Physicians also spoke of time pressures to manage their busy caseloads when weighing what to do: allocating additional time to LEP patients may limit the time they have available for others in need. Some participants spoke about translator 
Table 1 Supportive quotes for key findings

'Getting by' versus 'getting help' 'Getting by'

‘Getting help’

\section{Acuity, time constraints and availability of translation aids}

Acuity of clinical situation

Time constraints

Ease of use and availability of translation aids/interpreters (90708).
"If the patient speaks some English and I speak some French and a little bit of Spanish, if the answers seem appropriate to me and the patient doesn't demonstrate obvious concern about the interaction and it's relatively simple and not high-risk, then I would accept that communication is adequate." (90703) "I rely more heavily on my physical exam if I can't communicate with them, like l'd be more cautious with testing if I can't ask a specific question and be reassured"

"But somebody with chest pain or some funny neurologic symptom that you're worried could be a stroke, [it's] extremely difficult to treat without having a solid base of communication." (90901)

" ... [l'll] look for an interpreter or some staff that can come over and help.You know, somebody who speaks that language .... if they are stable you know and don't look like I need to do anything overly quickly for them and I really can't get a story out of them, then I'll ... get an interpreter first." (90708)

"So that's the problem you run into. You either try to strive to get a really good history through formal interpretation or you end up doing more testing of that person because you're worried about them more." (90614)

"It all depends on the clinical situation...I could almost treat a patient who cut their finger without talking to them at all... l'd want to make sure that their tetanus status was up to date, like there's a couple of things that you'd want to sort out, but by and large you could pretty much treat them without talking to them. But somebody with chest pain or some funny neurologic symptom that you're worried could be a stroke [it's] extremely difficult to treat without having a solid base of communication." (90901)

"So if a patient was sick, for example, had low pressure and a fast heart rate and still spoke no English, I would go in anyway and then just do what I consider to be paediatric medicine. Kids can't talk to you. You know they're two years old and they're crying and they're in pain-I can't get a history from a child the same way I can't get a history from someone who doesn't speak English." (91118)

"When we have a whole bunch of patients and we've got a busy schedule and we're already twenty minutes behind and so forth, you know we're looking for ways to be as efficient as possible. And if it looks like this patient can give us a few nods appropriately and say a few words that ... they should probably understand. We may be willing to just say okay well we've done our part." (90616)

"We sometimes take shortcuts and sometimes that's acceptable because the time that you save by taking shortcuts is justified because there are more important things that you need to spend your time doing." (90728)

"...if two people speak at the same time it can block out the sound and so it can become awkward but I would say that the two handset option is the best option followed by the speaker phone, followed lastly by the one handset option which is really, uh, it's enough to dissuade people from actually going to the language line." (90615)"there's a tremendous amount of resistance to going to the one handset: you'd almost rather this person just spoke a few words of English. You might just be inclined to do your best, try and see that they understand what 's actually taking place." (90728)

"If you're gonna continue this encounter without getting a translator, so if I'm sharp enough to know what this person's language is and it doesn't take long, then I may do a quick search locally, literally around me physically... in a clinic, on a ward, in the Emergency Department to see if someone who works in that department can speak that language and offer translation and there's a fair chance in Toronto you'll get a person who can speak that language fairly [easily]. And then that's the better route." (90710)

\section{A troubling space: dilemmas experienced in practice}

The 'grey zone'
"Well, I leave that to the patient to decide whether we need some kind of facilitator or an interpreter. You know I usually don't make the decision to say "how well you are comprehending what l'm saying and how well are you able to communicate to me?" So I usually ask them "would you like to have an interpreter present?" And 


\section{Table 1 Continued}

Dilemma of 'real world' vs 'ideal world' practice

Dilemma of responsibility

Dilemma of informed consent

Making language discordance a priority then they may say ' yes' or 'no'. The challenge is that in the real world we don't, we don't always end up having an interpreter readily available." (90615) "... so I sort of assess whether I need, whether I actually have time to wait for the interpreter and then l'd call and ask for an interpreter. I do use family members which is a bit of a grey zone because if there's a se...sensitive information you're no, so you're supposed to have an objective interpreter there, so I will sometimes use family members..." (90828)

"And they [patient] go 'um thank you'. And that's it, right. And so you kind of, you know clearly it's a suboptimal communication. There are a lot of things that you would really need to discuss to have this patient-centered care ideal. But you know the time that would be required to do that would be quite extensive and so we often take shortcuts that result in non-patient-centered care... It happens all the time frankly and I think well you know, we're probably less likely to do it in a situation where we really feel that it's critical." (90728)

"To be quite honest with you the ones I personally find the most helpful are family members. Because ... they can give you a little bit of the context, and then you can talk to them as well particularly if it's an elderly patient because not only do they translate for you but then they'll also say, 'You know what? Grandma hasn't been doing very well for a few months now. She hasn't been preparing her meals properly, she's been losing weight ... I'm concerned about Grandma." That's far more valuable to me in some respects than a translator who's just sticking to the letter of the law, and is saying exactly what they're supposed to, without kind of any context. It's just language right? I like the bigger picture." (90702)

"We've explained what's going on and they've nodded and kind of looked at me as though they're understanding - so now it's their responsibility, it's not mine any longer. I'm not suggesting that's the way that, you know I practice, but that's what can frequently happen in this grey zone. It's just enough English proficiency to be dangerous." (90615)

"They [patients/families with LEP] don't recognize that this is a ha-, a potential hazard...I think some of the responsibility lies with the patient." (90706)

"I don't think that's a responsibility that patient's necessarily carrying... That's not something I would expect of my families ... that's not a fair expectation I think." (90708)

"I can't get informed consent when I can't communicate." (90930)

"There have been circumstances in the past where we have been concerned as a group that families weren't accurately expressing our wishes to the patient or our statements to the patient and vice versa. And so there have been circumstances you know particularly in some of these [high] stakes circumstances where we will use professional translators regardless of the presence of the family to translate for just this reason." (90707)

"You know, we really have to get over the language barrier business because it's not going away-it's been here for a while and I don't think we've done a particularly good job until very recently-we're starting to address it-we should be very aggressive about prioritizing this subject." (90710) availability (eg, harder to reach during night shifts). One participant described a situation where it took 4 days for a translator to become available. Such delays influence not only the quality of care, but also hold cost implications if hospital length-of-stay is affected.

A third factor influencing whether to 'get by' or 'get help' was the ease of use/availability of translation aids/ interpreters. Some physicians admitted resistance to using technology-based interpretation. Although telephone-based language lines are designed to improve patient-physician communication, in practice, our participants reported that they can be awkward. Participants drew on a variety of experiences with language lines in different settings, indicating that all language lines are not created equal. For example, single handsets were seen as less preferable than the two handset option, although even with two handsets, it could be awkward if two people speak at the same time. Speaker phone was another option used.

\section{A troubling space: dilemmas experienced}

Participants expressed feeling conflicted at times over decisions to 'get by' or 'get help'. While they recognised that 'getting by' was often less-than-ideal, it was sometimes perceived as all that they could do. Such decisionmaking could be a source of anxiety. A participant 
noted that some patients have 'just enough proficiency for it to be dangerous' (90615). The language of 'danger' is significant, suggesting an unsettling and troubling experience for participants. A series of overlapping dilemmas constitute this troubling space, namely: the gap between real versus ideal practice, notions of responsibility and issues of informed consent.

\section{The dilemma of 'real world' versus 'ideal world' practice}

Physicians told of taking shortcuts and making judgment calls that, in some instances, could be considered acceptable practice. One participant said, 'the time that you save by taking shortcuts is justified because there are more important things that you need to spend your time doing' (90728). For example, participants recognised that using other staff members in the immediate vicinity who spoke the same language was not ideal, yet they would often opt for this approach as most efficient. In a similar vein, most participants indicated that using family members was not a preferred option; however one commented on what they saw as potential benefits of using family members-that, unlike professional interpreters, families were able to provide additional contextual information as well as the relative's perspective on the patient's condition during interpretation (90702). Despite these pragmatic considerations, most participants acknowledged that there is an optimal or 'best' way of providing care in these situations, namely the use of professional interpreters or translation aids.

There was a tension in many accounts between what they should do (based on recognised best practices in an ideal world) and what they ultimately can do at the bedside. They appear to use a sliding scale for decisionmaking, which is context-dependent, and allows them to gauge when 'getting by' can be justified.

\section{The dilemma of responsibility}

Participants expressed discomfort concerning who is ultimately responsible for ensuring adequate communication. While they recognised that they have an ethical obligation to ensure understanding, at the same time, some physicians appeared to put at least some of the onus on patients. In some situations, participants said they left the decision of whether communication was 'good enough' to the patient. They portrayed communication as a shared responsibility between physician and patient. However, they also depicted themselves as making their decisions about whether to get help as something they did on their own-they spoke at length about the information they deemed important, but said relatively little about what information patients might see as important.

\section{The dilemma of informed consent}

Another dilemma characterised by participants surrounded informed consent. In LEP situations, physicians may have to rely on professional translators or family members to secure consent. Family members as translators were of particular concern to participants.
Professional translators were perceived to be impartial and accurate when relaying information. Physicians expressed concern that family translators may change what is imparted due to personal biases or misinterpretations. Participants described a number of these situations, such as when patients and families appeared to differ in their wishes.

Participants acknowledged the issue of best practices with LEP patients as an important priority for physicians. A few participants took this sentiment a step further, warning that: 'We could even argue from an ethical or legal standpoint of course that we're obligated to ensure that there's appropriate communication' (90615). 'Patient-centred care' is espoused by hospitals and clinicians, and it is expected that treatment decisions will be made jointly between patient and provider. A principle of informed consent is that physicians provide the information patients need in order to make informed decisions; but gauging whether LEP patients have really understood the information provided can be challenging.

\section{DISCUSSION}

This study examined experiences of physicians working with LEP patients. Participants described two strategies for dealing with such situations: 'getting by' versus 'getting help.' The physicians in our study depicted their decisions to 'get by' as based on a judgment regarding whether communication was 'good enough' to proceed unaided, and depended on the specific circumstances. Participants characterised clinical encounters with LEP patients as a sometimes 'troubling' social space, presenting professional dilemmas. There was a tension between recognising what they should do (based on recognised best practices) and what they can do at the bedside (based on constraints of time and resources).

Our findings have important practice implications. For example, participants noted that in situations where they elect to 'get by', they conduct more tests on LEP patients to mitigate risk. There were no hard-and-fast rules for managing such risk; physicians told of making decisions in-the-moment, gauging the acuity/complexity of each patient's condition, circumstances, availability of translation aids/interpreters and their own caseload/ obligations to other patients. The threshold at which a physician shifts from getting by to getting help is variable, fluid and dependent on the individual and context. The suggestion that adequate communication is a shared responsibility presumes a team-based approach between physician and patient. However, team-based care usually implies open lines of communication, which is not the case in LEP. This may contribute to the sense of discomfort expressed by participants.

Discomfort may also stem partly from an underlying assumption that translation should be 'value neutral' and as 'objective' as laboratory testing. Translation during a clinical encounter is a social act, and as such is complex and contingent. Wong and Poon ${ }^{30}$ argue for 
translation being viewed 'not (as) a neutral technique of replacing words of one language with words of another' (p.152) but rather one imbued with meaning and interpretation on each side. Social context and power relations cannot be ignored. ${ }^{30}$ Rather than treating challenges presented by LEP as an inconvenience, they should be given priority and clinicians offered greater support.

It should be noted that data collection for this study took place in 2009, when fewer supports were available. At that time, relatively little orientation to interpretation services was offered to medical residents at the study facility, but now instruction regarding available interpretation services is being offered routinely. Training in language barriers and cultural competence is now gaining attention among medical educators. Telephone interpretation services continue to evolve and become more user-friendly; however other supports are still needed to make it easier for physicians to 'get help' when they need it. The study site has had policies relating to the provision of interpretation services for patients experiencing language barriers since at least the year 2000. These policies are aligned with the Canadian Charter of Rights and Freedoms as well as the Ontario Human Rights Act. The institution's policy on interpreter services in place at the time of the study (as well as the current one) refers to certain conditions where it is clear that professional interpreters are required (eg, signing of consent documents, provision of detailed discharge instructions) and in which the participants indicated that they felt confident in 'getting help' from professional interpretation services. All the physicians in our study expressed a desire to 'do the right thing', but acknowledged that pragmatic considerations (including the availability and ease-of-use of resources) might interfere with their ability to execute it to the level of the ideal. It was these instances that they sometimes found troubling. Busy caseloads and time constraints on clinical practice were and continue to be an issue for most clinicians. For example, it can take some time for an interpreter to be found for telephone interpretation (depending on the specific language required), which again takes time away from caring for other patients. The use of a language line presumes that there is always a telephone readily accessible at the bedside (eg, handset-based language line), which is not always the case, even in hospital settings. In cases where the language in question is relatively rare, there can be a waiting period to secure an appropriate translator even by telephone. In the city of Toronto, many different languages are spoken, which further adds to the complexity of the situation. When using in-person interpreters, aligning the schedules of the physician, professional interpreter and patient is frequently complex, with some physicians commenting that it can range from several hours to days before these sessions occur. This is confirmed by the findings from other researchers working with physicians and other healthcare practitioners. ${ }^{31} 32$
As a result, it is not surprising that in some circumstances, physicians opt for the 'path of least resistance' (which may include using another healthcare professional or a family member to interpret).

The implications for patients should not be underestimated. Rivadeneyra $e t a l^{4}$ indicate that situations of LEP negatively affect the provision of patient-centred primary care: even with the aid of interpreters, US physicians were less likely to probe further into symptoms of non-English-speaking patients. ${ }^{4}$ Clinical consequences of LEP can range from problems accessing care and treatment non-adherence, to higher mortality rates. ${ }^{1} 89$ Opportunities for gaining crucial insights may be missed (eg, understanding additional variables underlying presenting illness $)^{9}$ as may opportunities for developing rapport and trust, when physicians opt to 'get by'. ${ }^{33}$ Moreover, it has potential medicolegal consequences: how far should a physician go to ensure 'adequate' communication has been achieved in order to mitigate the potential of risk and harm? Participants are warranted in their characterisations of language discordant situations as troubling spaces.

Our study builds on prior work conducted by Diamond et al. ${ }^{31}$ They also used the phrase 'getting by' to describe their study's findings of medical residents' experiences of caring for patients in two US cities. Similar to our study, Diamond et al found that factors such as time constraints and convenience were cited as influencing participants' decisions to 'get by'. While our study confirms some of Diamond's findings and in another country/setting (with a very different healthcare system, and among other specialists), it also goes considerably further. Our study examined physicians' experiences with a variety of translation options (not just the use of professional in-person interpreters), and explored a range of perspectives that included those of experienced staff physicians as well as less experienced medical residents. This indicates that the phenomenon of 'getting by' is experienced by clinician trainees who are early in their professional lives, but also, more surprisingly, by seasoned senior staff. The habits developed during residencies evidently persist over time, and although these habits are characterised as unsettling they appear to be the status quo. This suggests that the issue of LEP should be more firmly embedded not only in medical school curricula, but in continuing education programmes as well. Our study goes further and offers an in-depth exploration of the dilemmas experienced that, according to participants, result from not being able to put the 'ideal' into practice. Diamond's ${ }^{31}$ participants were frequently unaware of standards of practice for interpretation in their settings, while participants in our study were acutely aware of what they should do, but frequently found this difficult to put into practice. Diamond's team did not appear to probe participants explicitly about what might be lost when a lot of clinical information is missing, while our participants 
seemed acutely aware of what might be missing and described how they tried to offset this by relying more heavily on diagnostic testing. Finally, our study explored the decision-making process of 'getting by' versus 'getting help' in richer detail, deepening our understanding of physicians' experiences.

While our study did not include the experiences of bilingual physicians, Maul et $a l^{33}$ and Regenstein et $a l^{34}$ have looked at physicians' willingness to 'get by' in situations where physicians and patients may share a language, but where physicians are less than fully fluent. Their findings indicate that even in these situations, physicians' non-English-language skills are highly heterogeneous, and that there is considerable risk of miscommunication. ${ }^{34}$ Physician-patient communication is complex (and often less-than-ideal) even when both parties share the same language. Our study illuminates how the addition of language barriers into the communicative space adds further layers of complexity.

There is a growing body of evidence indicating that employing the services of professional interpreters has important positive implications not only for clinical outcomes, but more effective healthcare utilisation (eg, improved preventive screening rates, reduced risk of hospitalisations). ${ }^{35} 36$ There is less compelling evidence that the use of professional in-person interpreters has negative impacts on duration of individual visits. ${ }^{36}$ The participants in our study spoke at length about time constraints, but this was often related to tracking down interpretation services and scheduling difficulties, rather than the length of the clinical encounter itself. It is possible that telephone interpretation may be able to offset the difficulties of scheduling in-person interpretation. Recent technological improvements in telephone interpretation/language lines and a greater number of options available since the time of the study suggest that these may be the most important solutions to invest in. Participants in our study indicated that physicians are most likely to follow the 'path of least resistance' for securing interpretation services, therefore implementation and testing of innovative, user-friendly telephone interpretation services should be a focus for future research.

Our study has limitations. As a single-centre study, its sample size might be considered small by quantitative standards. However, qualitative studies are meant to generalise the concepts generated, not to the population of physicians as a whole. ${ }^{21} 37$ As such the concepts of 'getting by' and 'getting help' are transferable to a wide range of practice settings. It might also be argued that the experiences of the physician participants presented here were shaped by a site-specific lack and/or inefficiency of resources. On the contrary, the study institution (a tertiary-care teaching hospital located in Canada's most diverse city) has systematically funded in-person and telephone-based translation services and has appropriate policies and procedures in place related to interpretation that have continued to evolve over the past decade. If physicians found it challenging to care for LEP patients in this setting, it is likely that those with access to fewer resources struggle even more.

Our study does not address cultural differences. Language and culture are inextricably linked and can result in differential access to care. ${ }^{48}$ Physician-patient miscommunication can also result from different cultural norms and understandings. ${ }^{39}$ This should be a focus for future research. Furthermore, due to the rapid rate of technological advances, wireless, telephone-based translation services have become more available in medical facilities. It is conceivable that previous obstacles to accessing timely professional translation services outlined here may be less of an issue currently. Data collection took place in 2009 and the telephone translation option has continued to evolve in the intervening period. Finally, our study does not address financial considerations. We understand that annual costs associated with in-person professional and technology-mediated translation services are not inconsiderable. This may represent a further constraint on putting the ideal of professional interpretation into practice. In a systematic review, Flores ${ }^{35}$ indicates that there are few studies related to costs of interpretation services. This should be a topic for further research.

This study begins to illuminate the difficult terrain of caring for LEP patients. In doing so, it opens up an opportunity to break the silence that exists among clinicians on this issue, and invites them to explore it. These doctors recognised that the shortcuts they are sometimes forced to take are less than ideal, but they also outlined the real-world constraints that make these shortcuts necessary in their current practice environment; and these environments are not conducive to doctors reflecting on the issue or even discussing it with their colleagues. We see our research as a catalyst for beginning this conversation. The dilemmas described here are likely encountered regularly by physicians practicing in large cities, in many jurisdictions, not just in Canada. Although time constraints, patient acuity and ease/availability of translation aids all play a role in physicians' decisions to 'get by' or 'get help', provision of more (and more userfriendly) language lines only partially addresses the issue. Improved support for physicians navigating this complex social space should be prioritised.

Author affiliations

${ }^{1}$ Applied Health Research Centre, Li Ka Shing Knowledge Institute, St Michael's Hospital, Toronto, Ontario, Canada

${ }^{2}$ Department of Physical Therapy and Graduate Department of Rehabilitation Science, University of Toronto, Toronto, Ontario, Canada

${ }^{3}$ Division of Emergency Medicine, Department of Medicine, University Health Network (Toronto General Hospital), Toronto, Ontario, Canada ${ }^{4}$ Department of Medicine, University of Toronto, Toronto, Ontario, Canada

${ }^{5}$ The Alternative Dispute Resolution Practice, Toronto, Ontario, Canada

Acknowledgements The authors wish to thank Caryl M Patrick for her assistance with data collection.

Contributors JAP contributed substantially to the interpretation and analysis of the data, as well as taking primary responsibility for drafting the 
manuscript. NAB contributed substantially to the analysis and interpretation of the data and participated in all phases of writing the manuscript. TS-G contributed to the conception and design of the study, assisted in the analysis and interpretation of data and assisted in drafting the manuscript. PLH took primary responsibility for the study's conception, design and data collection and contributed importantly to data analyses, interpretation and drafting of the manuscript. All authors read and approved the final version of the manuscript.

Funding This research received no specific grant from any funding agency in the public, commercial or not-for-profit sectors.

Competing interests At the time that the study was conducted, all authors were affiliated with the study institution (JAP, NAB and PLH were employees, and TSG was a residency trainee). At the time of publication, JAP and NAB continue to be employed by the study institution, while TSG and PLH are employed elsewhere.

Ethics approval St Michael's Hospital Research Ethics Board.

Provenance and peer review Not commissioned; externally peer reviewed.

Data sharing statement No additional data are available.

Open Access This is an Open Access article distributed in accordance with the Creative Commons Attribution Non Commercial (CC BY-NC 3.0) license, which permits others to distribute, remix, adapt, build upon this work noncommercially, and license their derivative works on different terms, provided the original work is properly cited and the use is non-commercial. See: http:// creativecommons.org/licenses/by-nc/3.0/

\section{REFERENCES}

1. Gardam M, Verma G, Campbell A, et al. Impact of the patient-provider relationship on the survival of foreign-born outpatients with tuberculosis. J Immigr Minor Health 2009;11:437-45.

2. Burnett A. Globalization, migration and health. Med Confl Surviv 2002;18:34-43.

3. Roberts C, Moss B, Wass V, et al. Misunderstandings: a qualitative study of primary care consultations in multilingual settings, and educational implications. Med Educ 2005;39:465-75.

4. Rivadeneyra R, Elderkin-Thompson V, Cohen Silver R, et al. Patient-centeredness in clinical encounters requiring an interpreter. Am J Med 2000;108:470-4.

5. Piette JD, Schillinger D, Potter MB, et al. Dimensions of patient-provider communication and diabetes self-care in an ethnically diverse population. J Gen Intern Med 2003;18:624-33.

6. Schillinger D, Piette J, Grumbach K, et al. Closing the loop: physician communication with diabetic patients who have low health literacy. Arch Intern Med 2003;163:83-90.

7. Bonds DE, Camacho F, Bell RA, et al. The association of patient trust and self-care among patients with diabetes mellitus. BMC Fam Pract 2004;5:26.

8. Schenker $\mathrm{Y}$, Lo B, Ettinger KM, et al. Navigating language barriers under difficult circumstances. Ann Intern Med 2008;149:264-9.

9. Morales LS, Cunningham WE, Brown JA, et al. Are Latinos less satisfied with communication by health care providers? J Gen Intern Med 1999;14:409-17.

10. Baker DW, Hayes R, Fortier JP. Interpreter use and satisfaction with interpersonal aspects of care for Spanish-speaking patients. Med Care 1998;36:1461-70.

11. Carasquillo O, Orav EJ, Brennan TA, et al. Impact of language barriers on patient satisfaction in an emergency department. J Gen Intern Med 1999;14:82-7.

12. Wilson E, Chen A, Grumback K, et al. Effects of limited English proficiency and physician language on health care comprehension. $J$ Gen Intern Med 2005;20:800-6.

13. John-Baptiste A, Naglie G, Tomlinson G, et al. The effect of English-language proficiency on length of stay and in-hospital mortality. J Gen Inter Med 2004;19:221-8.
14. Perez-Stable EJ, Napoles-Springer A, Miramontes JM. The effects of ethnicity and language on medical outcomes of patients with hypertension or diabetes. Med Care 1997;35:1212-19.

15. Papic O, Malak Z, Rosenberg E. Survey of family physicians' perspectives on management of immigrant patients: attitudes barriers, strategies, and training needs. Patient Educ Couns 2012;86:205-9.

16. Lovell BL, Lee RT, Brotheridge CM. Interpersonal factors affecting communication in clinical consultations: Canadian physicians' perspectives. Int J Health Care Qual Assur 2012;25:467-82.

17. $\mathrm{Ku}$ L, Flores $\mathrm{G}$. Pay now or pay later: providing interpreter services in health care. Health Aff 2005;24:435-44.

18. Masland MC, Lou C, Snowden L. Use of communication technologies to cost-effectively increase the availability of interpretation services in healthcare settings. Telemed $E$ Health 2010;16:739-45.

19. City of Toronto. Backgrounder-census 2011: language. Statistics Canada. Toronto: City of Toronto, 2012:1-22.

20. Morse JM, Richards L. Readme first for a user's guide to qualitative methods. Thousand Oaks: Sage Publications, 2002.

21. Kvale S. Interviews: an introduction to qualitative research interviewing. Thousand Oaks: Sage Publications, 1996.

22. Sandelowski M. Whatever happened to qualitative description? Res Nurs Health 2000;23:334-40.

23. Sandelowski M. What's in a name? Qualitative description revisited. Res Nurs Health 2010;33:77-84.

24. Miles MB, Huberman AM. Qualitative data analysis. Thousand Oaks: Sage Publications, 1994.

25. Crabtree BF, Miller WL. Using codes and code manuals. In: Crabtree BFMiller WL, eds. Doing qualitative research. 2nd edn. Thousand Oaks: Sage Publications, 1999:163-77.

26. Miller WL, Crabtree BF. The dance of interpretation. In: Crabtree BF, Miller WL, eds. Doing qualitative research. 2nd edn. Thousand Oaks: Sage Publications, 1999:127-43.

27. Pamphilon B. The Zoom model: a dynamic framework for the analysis of life histories. Qual Inquiry 1999;5:393-410.

28. Eakin JM, Mykhalovsky E. Reframing the evaluation of qualitative health research: reflections on a review of appraisal guidelines in the health sciences. J Eval Clin Pract 2003;9:187-94.

29. Frankel RM. Standards of qualitative research. In: Crabtree BF Miller WL, eds. Doing qualitative research. 2nd edn. Thousand Oaks: Sage Publications, 1999:333-46.

30. Wong JP-H, Poon MK-L. Bringing translation out of the shadows: translation as an issue of methodological significance in cross-cultural qualitative research. J Transcult Nurs 2010;21:151-8.

31. Diamond LC, Schenker Y, Curry L, et al. Getting by: underuse of interpreters by resident physicians. J Gen Intern Med 2009;24:256-62.

32. Taylor E, Jones F. Lost in translation: exploring therapists experiences of providing stroke rehabilitation across a language barrier. Disabil Rehabil 2014; early online:1-9.

33. Maul L, Regenstein M, Andres E, et al. Using a risk assessment approach to determine which factors influence whether partially bilingual physicians rely on their non-English language skills or call an interpreter. Joint Commission Qual Patient Saf 2012;38:328-36.

34. Regenstein M, Andres E, Wynia MK. Appropriate use of non-English language skills in clinical care. JAMA 2013;309:145-6.

35. Flores $\mathrm{G}$. The impact of medical services on the quality of healtcare: a systematic review. Med Care Res Rev 2005;62:255-99.

36. Karliner LS, Jacobs EA, Chen A, et al. Do professional interpreters improve clinical care for patients with limited English proficiency? A systematic review. Health Serv Res 2007;42:727-54.

37. Butler-Kisber L. Qualitative inquiry. London: Sage, 2010.

38. Taveras EM, Flores G. Why culture and language matter: the clinica consequences of providing culturally and linguistically appropriate services to children in the emergency department. Clin Pediatr Emerg Med 2004;5:76-84.

39. Lee SM. A review of language and other communication barriers in health care. Portland: US Department of Health and Human Services, 2003 